\title{
Applying Lean Six Sigma and Systematic Layout Planning to Improve Patient Transportation Equipment Storage in an Acute Care Hospital
}

\author{
Sandra Furterer, PhD, MBA and Pratheeka Kancharla, MS Engineering Management \\ ${ }^{1}$ University of Dayton, Engineering Management, Systems \& Technology Department, Dayton, \\ $\mathrm{OH}, \mathrm{USA}$ \\ Sfurterer1@udayton.edu
}

\begin{abstract}
Purpose:

The purpose of this project was to optimize the patient transportation process at an acute care hospital to achieve reduced transportation times.

\section{Methodology:}

A detailed Lean Six Sigma study on the patient transport and equipment handling processes helped to determine possible ways to reduce the equipment handling time which eventually reduces the patient transportation time. The Systematic Layout Planning (SLP) approach usually applied in manufacturing environments was used to identify which patient transport equipment was needed to be stored in which locations throughout the hospital footprint. The assignment of equipment to locations was determined based on frequency of use, distance, and equipment type.
\end{abstract}

\section{Findings:}

Key challenges were identified as lack of traceability of equipment, insufficient storage locations and storage locations with inappropriate equipment. Through SLP and statistical analysis of patient transport data, pickup locations were identified to minimize distance for high frequency trips for each mode of transport.

\section{Limitations:}

We provided the recommendations to the hospital to implement, but due to COVID pandemic resource issues they had not yet implemented the recommendations, although they are still planning to do so.

\section{Practical Implications and Originality/Value of Paper:}

The usage of the SLP approach combined with the Lean Six Sigma DMAIC method and tools was applied in the hospital environment to potentially reduce patient transport times, in what appears to be the first such research study applied to a hospital's patient transportation system.

Keywords: Patient transportation, Equipment, Systematic Layout Planning, Healthcare, Lean Six Sigma

Paper Type: Case Study 


\subsection{Introduction}

A detailed Lean Six Sigma study on a hospital's patient transport and equipment handling processes helped to determine possible ways to reduce the equipment handling time which eventually reduces the patient transportation time. The Systematic Layout Planning (SLP) approach usually applied in manufacturing environments was used to identify which patient transport equipment was needed to be stored in which locations throughout the hospital footprint. The assignment of equipment to locations was determined based on frequency of use, distance, and equipment type.

The hospital where this approach was applied is an acute care level-one trauma center in an urban setting, licensed for over 1,000 beds. The patient transportation department was a centralized department that provides transportation throughout the hospital, excluding the Emergency Department. The patient transportation time was not meeting their goals of transporting patients in under 30 minutes, and had extensive non-value-added activities, delays and wastes in the process. A local university partnered with the hospital to improve the patient transportation process through their graduate-level Lean Six Sigma for Engineers course. There were four graduate student team members, the instructor who was a certified Six Sigma Master Black Belt, the Vice President of Operations for the hospital, the Director and several process owners within the Centran (Central Transportation Department) who worked together on the project. After the initial Lean Six Sigma project findings and recommendations were provided to the hospital, one of the graduate students continued to work on the application of the SLP approach to improve transport equipment handling. The purpose of this project was to optimize the patient transportation process at an acute care hospital to achieve reduced transportation times and thus improved patient satisfaction. The remaining sections of the paper will include:1) a literature review on other hospitals and projects that applied Lean, quality and heuristic modeling methods to address patient transportation issues, applications of SLP applied in manufacturing environments, and a description of the Systematic Layout Planning technique; 2) the Methodology section describing the combination of the LSS DMAIC method with the Systematic Layout Planning; 3) the results of the applied methods; 4) the implications, limitations, conclusions and future research.

\subsection{Literature Review}

The health care system is quite complex. Large hospitals deal with thousands of patients every day. Patients are moved frequently throughout the hospital as they receive services including moving from the Emergency Department to the inpatient floors, from one inpatient unit or floor to another, from inpatient rooms to imaging, or special procedures areas, as well as to be discharged from the hospital. They need to have an efficient patient transportation process to avoid delays, to gain patient's satisfaction and confidence and to escape any unnecessary costs and activities incurred due to patient transportation delays. To achieve the intended results in patient transportation, one must go through a deep-dive analysis of the data and adopt some appropriate methodologies that can be applied to address the pain areas.

Chiarini (2013) illustrated how specific tools derived from Lean Thinking (Womack and Jones, 1991) such as value stream mapping (Rother and Shook, 199), a spaghetti chart, and activity worksheet helped to reduce costs related to patient transportation and other kinds of wastes (Ohno, 1988), (Hounshell, 1984). In another study, the researchers applied quality tools to improve the 
patient transfer process in a research institute hospital (Samragi, 2018) conducted a study on the intra-patient transfer process at Fortis Memorial Research Institute, Gurgaon, India to analyze the process, processing time and personnel involved in the transfer procedure.

The next work described applying simulation techniques to improve the patient transportation system in a large hospital. This work by Segev, Levi, Dunn, and Sandberg (2012) modeled the impact of changing patient transportation systems on peri-operative process performance in a large hospital. A research study applied dynamic modeling with a two-phase heuristic procedure to improve the patient transportation time in a German hospital (Beaudry, Laporte, Melo, and Nickel, 2010). In this study they were able to reduce waiting times for patients while using fewer vehicles. Another study modeled combined hospital layout information with patient and staff information, and information provided by sensor readings that captured the location of the transports to provide a self-learning module that learned the causes of transport delays (Bonte, Ongenae, and Turck, 2019).

Nagi and Altarazi (2017) implemented the Six Sigma DMAIC method along with lean tools and a facility layout technique to reduce the occurrence of nonconformities in the carpeting process which can be used in several industries including construction, aviation, and automotive. Suhardini, Septiani, and Fauziah (2017) worked on the problems with the layout in a construction product manufacturing plant and applied the Systematic Layout Planning approach combined with simulation modeling.

Based on the authors literature search, there appears to be no research that combined the Lean Six Sigma DMAIC approach combined with the Systematic Layout Planning technique to improve patient transportation and transportation equipment storage in a hospital setting.

\subsection{Methodology}

The Lean Six Sigma (LSS) DMAIC (Define-Measure-Analyze-Improve-Control) methodology and tools were used along with the Systematic Layout Planning (SLP) methodology to identify improvement recommendations to reduce the time searching for equipment and transporting the patients from one location in the hospital to another. Within the Measure phase, patient transportation data was collected for analysis in the Measure and Analyze phases. Patient transport data was extracted from the patient transportation information system that included the transport mode, equipment type, status, pickup location, destination location, month, day of week, hour of the day, and time to transport the patient. Qualitative data was also collected from the transporters to understand the challenges faced in the transportation process through interviews and a survey.

Finally, the Systematic Layout Planning (SLP) technique was used to improve the layout design related to the storage of the equipment used to transport patients, including beds, carts, wheelchairs, specialty wheelchairs, and special video fluoroscopy chairs. The Systematic Layout Planning (SLP) method, evaluation and implementation of the optimized design are the key motives of the layout analysis. PQRST, which is an acronym for Production, Quantity, Routing, Supporting Services and Time is a tool used to unlock layout problems. Product (or service) and Quantity (or volume) are the two basic elements on which any layout problem resides. In this case, the product would be to fulfil a patient transport request and the quantity is the number of requests 
being worked upon in a given period. Three fundamentals of SLP are Relationships between activities, Space for each activity and Adjustments. The approach begins with the analysis of the Inputs (using the PQRST tool) and leads to the output, Activity-Areas (departments, workgroups, cells etc.,). In this context, some of the key activity areas could be current equipment storage locations, pickup locations, and destination locations. This is followed by the visualization of the relationships through Flow of Materials. The Material Flow Chart tool assists with defining the flow of materials between the activity areas identified. The flow of materials here can be referred to as the travel of the transporter between equipment storage locations, pick up and destination locations. Inputs from the above 2 steps can be used to develop a Relationship Diagram which can further be used to identify the adjustments required to the layout and can result in various Alternative Layouts. Finally, the evaluation of each layout is done to find out the best and feasible solutions that can be implemented.

Once the activity areas are identified, the relationship between them should be noted. For instance, which pickup locations use which equipment storage locations, what are all the pickup locations requested for a destination and finally which of these locations have a trip required. The average speed of the transporters for each equipment mode of the transport were calculated by either working with a transporter in person or collecting the information from transporters based on their experience. Finally, the distances between the pickup, destination and equipment storage locations calculated through walking to various locations and noting the approximate steps. Combining the average speed of a transporter with the approximate distances covered would result in the time taken to travel each distance.

Next we will describe the results of the combined LSS DMAIC project with the SLP technique.

\subsection{Results}

The SLP required data was collected within the LSS DMAIC Measure phase, used within the Analyze phase as part of the analysis of the data collected to identify the number of trips, the equipment used, and the frequency of trips between locations, and then in the Improve phase to develop potential equipment storage locations based upon the data collected and the analysis of the data.

The transport time data used was from the when the dispatcher assigned the order to the transporter, to the order being acknowledged by the transporter, to the order being placed in progress by the transporter and until it is complete (when the patient is delivered). We developed a general linear model using ANOVA to analyze the effect of the patient transport variables including priority, mode, number of transporters, hour of day, and day of week. The significant variable was discovered to be the equipment mode of transportation, namely whether a bed, cart, wheelchair, fluoroscopy chair, etc., was used to transport the patient. Figure 1 shows the differences in the frequency and transport times by equipment mode. 


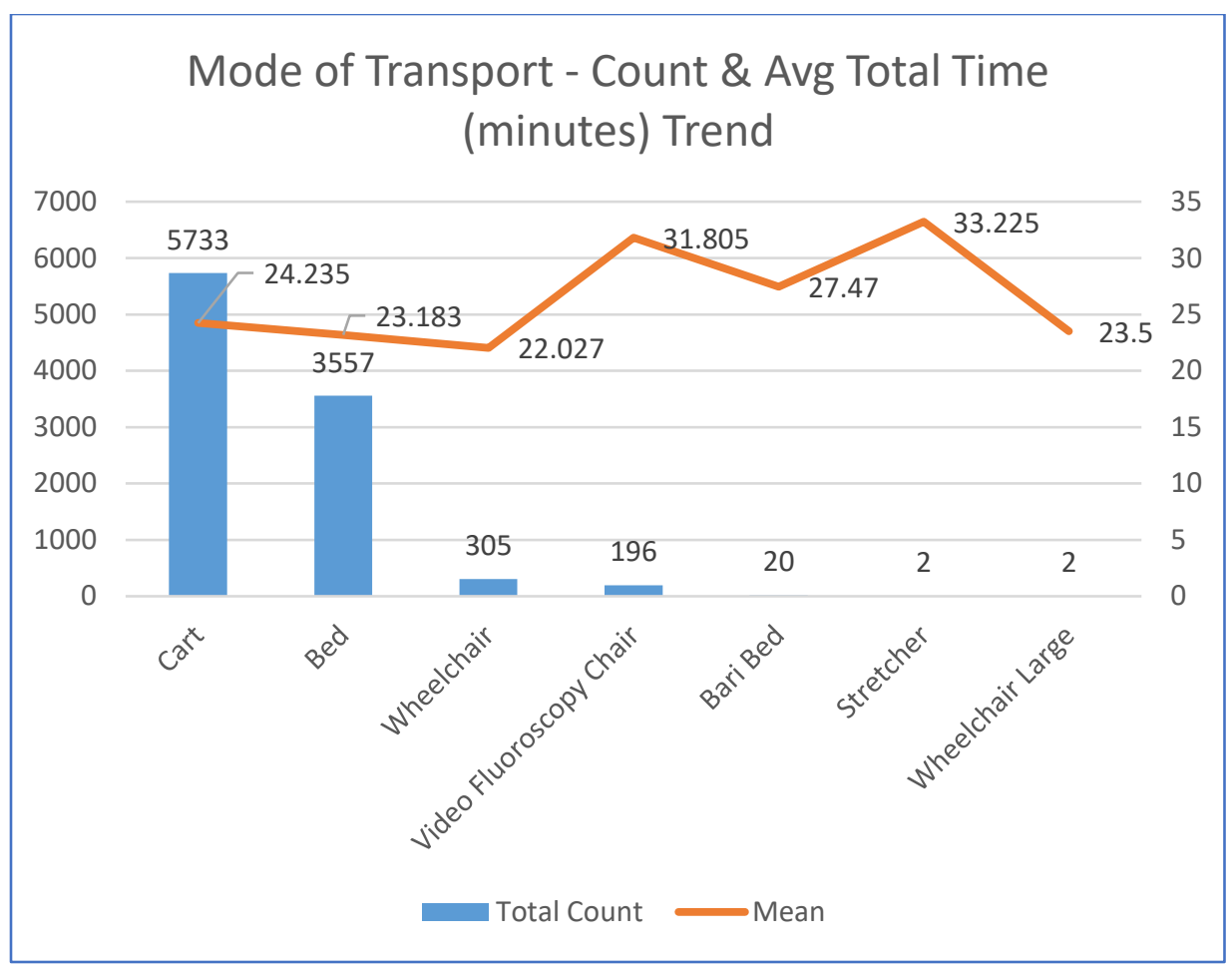

Figure 1 Mode of Transport - Count \& Average of Total Time

\section{Equipment Capacity Analysis}

We analyzed the demand for the different types of equipment (wheelchairs, carts and video fluoroscopy chairs) and compared this demand to the number of each equipment type available. This analysis showed that there were enough equipment available assuming that the equipment counts shared are available and in working condition.

\section{Qualitative analysis}

A questionnaire was used to gather the inputs from the transporters on the challenges faced in the entire patient transportation process. Results of which are shown by the affinity diagram shown in Figure 2. 


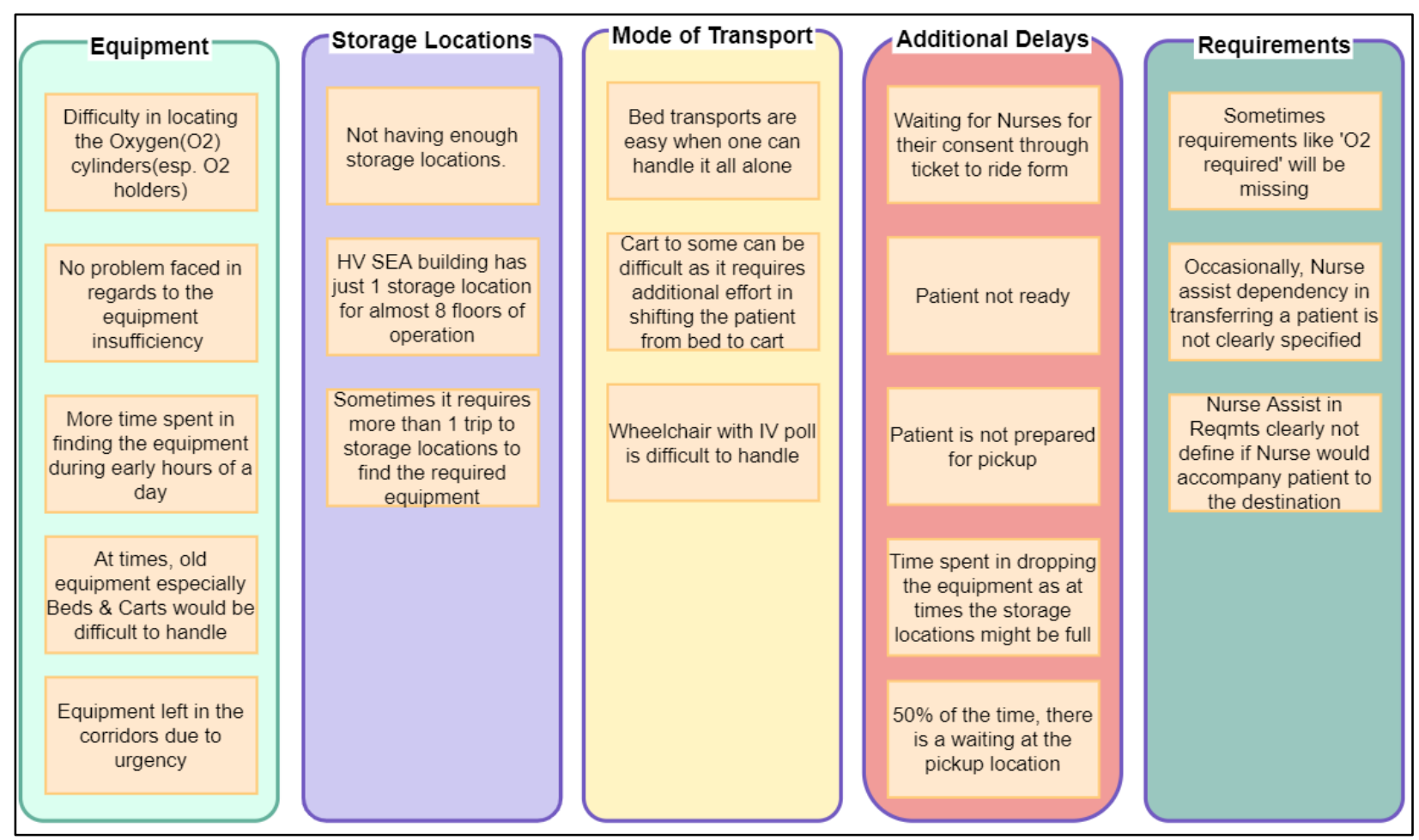

Figure 2 Transporter's response affinity diagram

Based on the transporter's feedback and the observations made during the travel with the Centran team on the real-time transport requests, having additional storage locations and the ability to track the equipment has a great potential to improve the overall transportation time and thus increase the transporter's efficiency.

The number of steps was recorded between the first nearest storage to the pickup location, the first nearest to the second nearest storage and the second nearest storage to the pickup location. Around 1047 of 1893 trips are from the South East building $6^{\text {th }}, 7^{\text {th }}, 8^{\text {th }}, 9^{\text {th }}, 10^{\text {th }}$ floors which represents that $55 \%$ of the trips are from the floors specified in the South East (SE) building.

We then created a chart of distances multiplied by the number of trips, which was used to determine the required storage locations. Approximately $44 \%$ of the total distance is covered between the HV SEA $1^{\text {st }}$ floor storage to other locations and around $26 \%$ of the total distance is covered between the Main building $6^{\text {th }}$-floor storage to other locations. Since a majority of the requests are from the $6^{\text {th }}$ to the $10^{\text {th }}$ floors of the SE building, it is advisable to have one storage location somewhere in these referred floors of the SE building instead of the $1^{\text {st }}$ floor.

When it comes to the Main building $6^{\text {th }}$-floor storage, nearly $85 \%$ of the distance is between the $6^{\text {th }}$-floor storage and to the SE building locations in the $6^{\text {th }}$ to the $10^{\text {th }}$ floors. This once again confirms that the $6^{\text {th }}$-floor storage is used frequently for pickups in the SE building.

Seventy percent of the wheelchair's requested from all the above-stated pickup locations are from the $\mathrm{SE}$ building $6^{\text {th }}$ to the $10^{\text {th }}$ floors. So, having wheelchairs stored in the location that is closer to the said floors would bring down the equipment pickup times for wheelchairs. Similarly, in the 
case of Video fluoroscopy chairs, we see $50 \%$ of the requests are from the SE building and the rest are from the main building $3^{\text {rd }}$ and $4^{\text {th }}$ floors. Hence splitting the chairs between the $1^{\text {st }}$-floor storage and the storage in the SE building should reduce the time.

\section{Recommendations}

- The equipment tracking system is one of the main recommendations from the above analysis as the transporters spend a considerable amount of time in tracking the equipment. This would enable the transporters to attend to the patients quicker.

- Based on the SLP analysis, additional storage is required in the South East building $6^{\text {th }} / 7^{\text {th }}$ $/ 8^{\text {th }}$ floors as around $44 \%$ of the pickups are being done from the SE building $6^{\text {th }}$ to $10^{\text {th }}$ floors.

- After analyzing the data, it is advisable to have $30 \%$ of the carts in the main building $6^{\text {th }}$ floor storage, $30 \%$ of them should be in the new storage location (in either SE 6, 7, 8 floors) and the rest (40\%) can be distributed between various other storage locations.

- Seventy percent $(70 \%)$ of the wheelchairs are recommended to be stored in a location nearer to the SE building $6^{\text {th }}$ to the 10th floors.

- Video fluoroscopy chairs are to be distributed between the $1^{\text {st }}$-floor storage and the storage location nearest to the SE building $6^{\text {th }}$ to $10^{\text {th }}$ floors.

\subsection{Implications, Conclusions, Limitations, and Future Research}

The Lean Six Sigma DMAIC method provided the framework for performing the SLP technique. Although it felt like the hospital did not have enough equipment, it was shown that they did in fact have enough equipment, but it was not easily found, nor stored closest to where it was most frequently used. The application of the SLP technique which began in manufacturing plants to streamline the layout of equipment to reduce movement of parts and materials is shown to be a powerful, yet straight forward tool that provided excellent insights for the hospital's equipment storage, as a first of its kind in the research. This technique could be applied in other hospitals and in other processes within the same hospital. The use of this tool demonstrates that without data and without using the data in a systematic manner, the problem can appear much more complex and unsolvable than it is. So many of the patient transporters just put up with the problems, yet their knowledge of the processes coupled with the data and a systematic tool, helped to unlock the solutions, that could be implemented without large expenses. We provided the recommendations to the hospital to implement, but due to COVID pandemic resource issues they had not yet implemented the recommendations, although they are still planning to do so. For future research, development of a simulation model to simulate the impact on patient transportation times and delays could further prove out the revised recommended equipment storage locations prior to the physical implementation of these locations. This could be extremely valuable since storage in hospitals is almost always at a premium.

\section{References}

Beaudry A, Laporte G, Melo T, Nickel S. (2010). Dynamic transportation of patients in hospitals. OR Spectrum. 2010;32(1):77-107. doi:10.1007/s00291-008-0135-6 
Bonte P, Ongenae F, Turck FD. (2019). Towards Optimizing Hospital Patient Transports by Automatically Identifying Interpretable Causes of Delays. International Journal of Software Engineering $\quad \& \quad$ Knowledge $\quad$ Engineering. $\quad 2019 ; 29(6): 819-847$. doi:10.1142/S0218194019500281

Chiarini, A. (2013). Waste savings in patient transportation inside large hospitals using lean thinking tools and logistic solutions. Leadership in Health Services.

Hounshell, D.A. (1984), From the American System to Mass Production, 1800-1932: The Development of Manufacturing Technology in the United States, Johns Hopkins University Press, Baltimore, MD.

Muther, R. (1973) 4th edition. Systematic Layout Planning/by Richard Muther (No. 658.5 m8.).

Ohno, T. (1988), Toyota Production System: Beyond Large Scale Production, Productivity Press, New York, NY.

Nagi A, Altarazi S. (2017). Integration of Value Stream Map and Strategic Layout Planning into DMAIC Approach to Improve Carpeting Process. Journal of Industrial Engineering and Management. Accessed April 25, 2021.

http://search.ebscohost.com.libproxy.udayton.edu/login.aspx?direct=true $\& d b=e d s r a c \& A N=e$ dsrac.321701\&site $=$ eds-live

Rother, M. and Shook, J. (1998), Learning to See, The Lean Enterprise Institute, Brookline, MA.

Samragi, M. (2018). A Prospective Study of Internal Transfer Delays In A Private Hospital Of North India. Retrieved June 15, 2020, from http://www.iosrjournals.org/iosrjbm/papers/Vol20-issue10/Version-1/F2010014451.pdf

Segev, D., Levi, R., Dunn, P. F., \& Sandberg, W. S. (2012). Modelling the impact of changing patient transportation systems on peri-operative process performance in a large hospital: insights from a computer simulation study. Health care management science, 15(2), 155-169.

Suhardini, D., Septiani, W., \& Fauziah, S. (2017, December). Design and simulation plant layout using systematic layout planning. In IOP Conference Series: Materials Science and Engineering (Vol. 277, No. 1, p. 012051). IOP Publishing.

Womack, J.P., Jones, D.T. and Ross, D. (1991), The Machine that Changed the World: The Story of Lean Production, Harper Collins, New York, NY. 